\title{
The Relationship Between UBE2C and AGGFI Overexpression and Tumor Angiogenesis in Non-Small Cell Lung Cancer
}

\author{
Yufei Wang ${ }^{1} *$ \\ Fan Shi ${ }^{1, *}$ \\ Run $\mathrm{Tao}^{2, *}$ \\ Jiatao $\mathrm{Wu}^{\mathrm{l}}$ \\ Jinxiang $\mathrm{Gu}^{\prime}$ \\ Ruixue Yang' \\ Shiwu Wu (1D)
}

'Department of Pathology, The First Affiliated Hospital of Bengbu Medical College, Bengbu, People's Republic of China; ${ }^{2}$ Department of Urology, The First Affiliated Hospital of Bengbu Medical College, Bengbu, People's Republic of China

*These authors contributed equally to this work
Correspondence: Shiwu Wu Department of Pathology, The First Affiliated Hospital of Bengbu Medical College, No. 287, Changhuai Road, Bengbu, Anhui, 233003, People's Republic of China

Email 13705523357@I63.com
Background: Tumor infiltration and metastasis are the leading causes of death for patients with tumors. Angiogenesis is a prerequisite for tumor growth and metastasis. Angiogenic factor with $\mathrm{G}$ patch and FHA domains 1 (AGGF1) is an angiogenic factor, whereas ubiquitin-conjugating enzyme E2C (UBE2C) functions in protein ubiquitination. Microvessel density (MVD) is the most common indicator of tumor microvessels, and vasculogenic mimicry (VM) facilitates blood supply to tumors. This study explored UBE2C and AGGF1 expression in non-small cell lung cancer (NSCLC) and their relationship with angiogenesis and prognosis to identify biological factors that might predict NSCLC infiltration, metastasis, and prognosis.

Methods: The specimens and clinical pathological data of patients with NSCLC confirmed by pathology after surgical resection between January 2013 and December 2015 were collected. UBE2C and AGGF1 expression, as well as microvessel formation and VM in NSCLC, was observed using immunohistochemistry. The relationships between UBE2C, AGGF1, MVD, VM, and clinical pathological parameters and their relationships with overall survival (OS) and disease-free survival (DFS) were analyzed.

Results: UBE2C and AGGF1 levels in NSCLC tissues were significantly higher than those in corresponding normal tissues $(57.1 \%$ vs 15.6 and $59.7 \%$ vs $25.3 \%$, respectively; $P<0.05$ ). UBE2C, AGGF1, MVD, and VM were positively correlated with each other $(P<0.05)$ and were all related to tumor size, lymph node metastasis, and tumor-node-metastasis stage $(P<$ 0.05). Kaplan-Meier analysis showed that patient OS and DFS in the UBE2C, AGGF1, VMpositive, and high-MVD groups were reduced (all $P<0.001$ ). Univariate and multivariate analyses showed that UBE2C, AGGF1, VM, and MVD were independent risk factors for NSCLC prognosis.

Conclusion: UBE2C and AGGF1 overexpression is associated with angiogenesis and poor prognosis and may be important for predicting NSCLC invasion, metastasis, and prognosis. Keywords: UBE2C, AGGF1, tumor angiogenesis, non-small cell lung cancer, biomarker, prognosis

\section{Introduction}

The latest research results show that there were approximately 10 million cancer deaths worldwide in 2020, of which approximately 1.8 million were due to lung cancer. ${ }^{1}$ Lung cancer remains the most common cause of cancer-related deaths, and its incidence continues to increase. ${ }^{1}$ In most countries, the 5-year survival rate of lung cancer is only $10-19 \% .^{2}$ More than $80 \%$ of lung cancers are further classified as non-small cell lung cancer (NSCLC) and are already in an advanced stage when 
the diagnosis is confirmed. ${ }^{3}$ Chemotherapy is no longer the most sought-after important treatment modality for patients with advanced and metastatic NSCLC because targeted therapy has less adverse reactions and can improve the prognosis. ${ }^{4}$ Tumor infiltration and metastasis are hallmarks of malignant tumors and are the main causes of death in patients with these diseases. ${ }^{5}$ Therefore, it is essential to identify the biological factors that might predict the infiltration, metastasis, and prognosis of NSCLC.

The study of tumor angiogenesis has always been an important topic in the field of oncology. When the oxygen provided by the vascular system in the tumor tissue cannot meet the needs for rapid tumor cell growth, new blood vessels are formed based on the original vascular system, and this process is called tumor angiogenesis. ${ }^{6}$ Angiogenesis is closely related to tumor progression and it makes tumors more prone to metastasis and recurrence; thus, highly vascularized NSCLC tends to be associated with a poor prognosis. ${ }^{5,7}$ Currently, microvessel density (MVD) is the most commonly used indicator to evaluate angiogenesis. ${ }^{8}$ In vasculogenic mimicry (VM), a tube surrounded by tumor cells lined with a periodic acid-Schiff (PAS)-positive basement membrane is formed. The blood in this vessel is transferred via the tumor microvessels. ${ }^{9}$ Because the tumor cells constituting VM are in direct contact with the blood, they can easily enter circulation and contribute to distant metastasis. ${ }^{10}$

Ubiquitin-conjugating enzyme E2C (UBE2C) is a key component of the ubiquitin-proteasome system. It binds ubiquitin molecules to target proteins that are then degraded by the 26-S proteasome. Overexpression of UBE2C induces tumorigenesis by inducing chromosomal hysteresis and the production of aneuploid cells. ${ }^{11}$ UBE2C level is almost undetectable in normal tissues; however, it is overexpressed in many cancers. ${ }^{12-16}$ Studies have shown that UBE2C is related to multiple biological behaviors, such as tumor occurrence, proliferation, invasion, and apoptosis. ${ }^{11,14,15}$ Previous studies have shown that UBE2C may have a regulatory effect on tumor angiogenesis; ${ }^{17,18}$ however, the relationship between UBE2C and MVD and VM in NSCLC remains unclear.

The angiogenic factor with $\mathrm{G}$ patch and FHA domains 1 ( $A G G F 1)$ gene was discovered by Tian et al in 2004; they reported that the gene was highly expressed in vascular endothelial cells in patients with congenital venous malformation osteotome syndrome. ${ }^{19}$ Studies have confirmed that AGGF1 plays a vital role in maintaining vascular functions, including vascular integrity and stability, and it is necessary for tumor angiogenesis; furthermore, the AGGF1-PI3K-AKT signaling pathway also plays a key role in tumor angiogenesis. ${ }^{20}$ It has been reported that AGGF1 level is upregulated in various types of human cancers, such as glioblastoma, colorectal cancer, liver cancer, gastric cancer, and esophageal cancer. ${ }^{21-25}$ However, the expression of AGGF1 in NSCLC and its relationship with angiogenesis have not yet been reported.

As the role of UBE2C and AGGF1 in promoting angiogenesis in NSCLC has yet to be elucidated, we used immunohistochemistry to simultaneously detect the levels of UBE2C, AGGF1, MVD, and VM in NSCLC to explore the effects of UBE2C and AGGF1 on angiogenesis, their relationship, and prognosis.

\section{Materials and Methods Patients and Tissue Specimens}

We randomly selected 154 patients who underwent radical surgery for lung cancer between January 2013 and December 2015, who did not receive any anti-cancer treatment before surgery, and were confirmed to have lung squamous cell carcinoma (SCC) or lung adenocarcinoma (Ade) by immunohistochemistry after surgery. Paraffin specimens with cancerous and corresponding normal tissues were selected from these patients. To evaluate the survival status of patients after surgery in a timely manner, the patients were followed-up by telephone every 6 months. The overall survival (OS) was recorded as ending in the patient's death by December 2020, and the disease-free survival (DFS) was recorded as ending in the patient's relapse or death by December 2020. This study was conducted with the written informed consent of all patients and approval from the Ethics Committee of Bengbu Medical College (NO. 2020KY035) in accordance with the ethical guidelines of the Declaration of Helsinki. The tumor-nodemetastasis (TNM) stage was determined according to the 8th edition of the American Joint Commission on Cancer lung cancer staging system. The clinical pathological parameters of the patients are presented in Table 1.

\section{Immunohistochemistry}

The selected paraffin specimens were successively cut into $4-\mu \mathrm{m}$-thick tissue sections. Slices were soaked for $2 \mathrm{~h}$, dewaxed with xylene, dehydrated with gradient alcohol, and then washed with distilled water and phosphatebuffered saline (PBS) thrice, each for $3 \mathrm{~min}$. To retrieve the antigens, the sections were subjected to boiling in citric 
Table I Patients Characteristics

\begin{tabular}{|c|c|c|}
\hline Patients Characteristics & Frequency (n) & Percentage (\%) \\
\hline \multicolumn{3}{|l|}{ Age (years) } \\
\hline$<60$ & 51 & 33.1 \\
\hline$\geq 60$ & 103 & 66.9 \\
\hline \multicolumn{3}{|l|}{ Gender } \\
\hline Female & 50 & 32.5 \\
\hline Male & 104 & 67.5 \\
\hline \multicolumn{3}{|l|}{ Smoking } \\
\hline No & 88 & 57.1 \\
\hline Yes & 66 & 42.9 \\
\hline \multicolumn{3}{|l|}{ Tumor size $(\mathrm{cm})$} \\
\hline$\leq 3$ & 77 & 50.0 \\
\hline$>3$ & 77 & 50.0 \\
\hline \multicolumn{3}{|l|}{ Gross Type } \\
\hline Central & 87 & 56.5 \\
\hline Peripheral & 67 & 43.5 \\
\hline \multicolumn{3}{|l|}{ Histologic Type } \\
\hline SCC & 76 & 49.4 \\
\hline Ade & 78 & 50.6 \\
\hline \multicolumn{3}{|l|}{ Grade } \\
\hline Well & 28 & 18.2 \\
\hline Moderate & 85 & 55.2 \\
\hline Poor & 41 & 26.6 \\
\hline \multicolumn{3}{|l|}{ LNM } \\
\hline No & 71 & 46.1 \\
\hline Yes & 83 & 53.9 \\
\hline \multicolumn{3}{|l|}{ TNM stage } \\
\hline I+II & 93 & 60.4 \\
\hline III+IV & 61 & 39.6 \\
\hline
\end{tabular}

Abbreviations: SCC, squamous cell carcinoma; Ade, adenocarcinoma; LNM, lymph node metastasis; TNM, tumor-node-metastasis.

acid buffer ( $\mathrm{pH} 6.0$ ), cooled to $20^{\circ} \mathrm{C}$, and rinsed again with PBS, as described above. To inhibit endogenous peroxidase, $3 \% \mathrm{H}_{2} \mathrm{O}_{2}$ was added dropwise to the sections and rinsed with PBS for 9 min after 10-20 min. Rabbit polyclonal anti-AGGF1 (1:100; AB_2844914, Affinity Biosciences), rabbit monoclonal anti-UBE2C (1:1000; ab252940, Abcam), and anti-CD34 (1:200; ab762, Abcam) antibodies were added dropwise onto the different sections and incubated overnight at $4^{\circ} \mathrm{C}$. Subsequently, the sections were incubated with secondary antibodies for 30 min. Finally, the 3,3'-diaminobenzidine (DAB) solution and the hematoxylin solution were sequentially added dropwise to the slices, which were washed with distilled water and then placed in a gradient of alcohol for dehydration.

\section{Evaluation of Staining}

The immunohistochemical results of the sections were evaluated by two experienced pathologists. The immunohistochemical scores for UBE2C and AGGF1 proteins were determined by the proportion of positive cells in tumor tissue $(0,<10 \% ; 1,11-50 \% ; 2,51-75 \% ; 3,>$ $75 \%)$ and staining intensity ( 0 , no staining; 1 , pale yellow staining; 2, tan staining; 3 , brown staining); the final score was the product of these two values. If the total score was $\geq 3$, it was determined positive; otherwise, it was considered negative. MVD was determined according to the method described by Weidner et al. $^{26}$ The vascular endothelium was labeled with CD34, and the most densely populated area of microvessels was observed under 100fold magnification. The microvessels in three different areas were then counted under 400-fold magnification, and the average number was calculated as the MVD of the tumor. We demonstrated the structure of VM by double staining with PAS and CD34. When CD34 was negative and PAS was positive, VM was considered to exist in the tumor.

\section{Statistical Methods}

Statistical analyses were performed using SPSS 25.0. The relationships among UBE2C, AGGF1, MVD, VM, and clinical pathological parameters were analyzed using the Chi-square test. The correlations among UBE2C, AGGF1, MVD, and VM were determined using Spearman correlation analysis. Kaplan-Meier analysis was used to compare the factors with OS and DFS. Univariate and multivariate Cox regression models were used to identify risk factors affecting prognosis. Statistical significance was set at $P<0.05$.

\section{Results}

\section{Relationships Between UBE2C, AGGFI, MVD, or VM and Clinicopathological \\ Parameters}

We first analyzed the expression of UBE2C, AGGF1, MVD, and VM in NSCLC using immunohistochemistry and statistical software. UBE2C was present in both the nucleus and cytoplasm and was prominently expressed in cancer tissues (57.1\%, 88/154; Figure 1A) but was rarely expressed in normal lung tissue $(15.6 \%, 24 / 154$; Figure 1B). The expression level of UBE2C in NSCLC tissues was significantly correlated with tumor size $(P=0.003)$, lymph node 

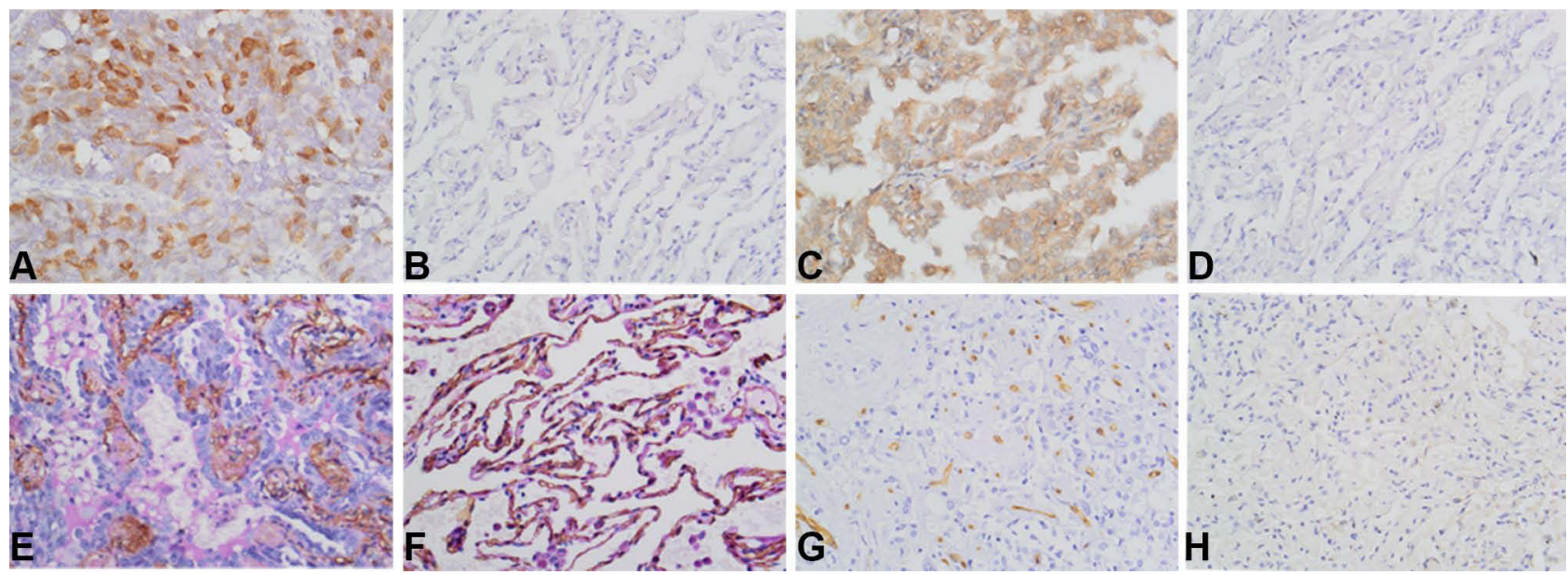

Figure I Immunostaining of UBE2C, AGGFI, VM and MVD in NSCLC and control tissues. (A) Positive staining of UBE2C in NSCLC tissues ( $\times 400)$. (B) Negative staining of UBE2C in control tissues ( $\times 400$ ). (C) Positive staining of AGGFI in NSCLC tissues ( $\times 400)$. (D) Negative staining of AGGFI in control tissues $(\times 400)$. (E) Positive staining of VM in NSCLC tissues ( $\times 400)$. (F) Negative staining of VM in control tissues ( $\times 400)$. (G) High MVD in NSCLC tissues ( $\times 400)$. (H) Low MVD in control tissues ( $\times 400)$. Abbreviations: NSCLC, non-small cell lung cancer; UBE2C, ubiquitin-conjugating enzyme E2C; AGGFI, angiogenic factor with Gpatch and FHA domains I; VM, vasculogenic mimicry; MVD, the microvessel density.

metastasis (LNM; $P=0.005)$, and TNM stage $(P=0.001$; Table 2) but not with age, sex, or other parameters $(P>0.05$; Table 2). AGGF1 was mainly localized in the cytoplasm, and its expression rate in cancer tissues was 59.7\% (92/154; Figure $1 \mathrm{C}$ ), which was higher than that in normal lung tissue (25.3\%, 39/154; Figure 1D). The expression of AGGF1 was closely related to tumor size $(P=0.009), \operatorname{LNM}(P=0.002)$, and TNM stage $(P=0.028$; Table 2$)$ but was not related to other parameters $(P>0.05$; Table 2$)$.

VM was observed in 56 of 154 NSCLC tissues (36.4\%; Figure 1E) but not in normal tissues (Figure 1F). VM positivity was positively correlated with tumor size $(P=0.003)$, LNM $(P<0.001)$, and TNM stage $(P=0.001$; Table 2$)$ but not with age, sex, smoking status, gross type, histological type, and tumor grade ( $P>0.05$; Table 2$)$. The mean MVD values in NSCLC and normal lung tissues were $35.00 \pm 1.47$ and 15.31 \pm 0.71 (Figure $1 \mathrm{G}$ and $\mathrm{H}$ ), respectively. Based on the mean MVD of the cancerous tissue, the patients were divided into high- $(\geq 35.00)$ and low-MVD groups $(<35.00)$. The results showed that MVD was positively correlated with tumor size $(P=0.009)$, LNM $(P=0.002)$, and TNM stage $(P=0.009$; Table 2$)$ but not with other parameters $(P>0.05$; Table 2).

\section{Relationships Among UBE2C, AGGFI, MVD, and VM}

UBE2C expression was positively correlated with AGGF1 expression $(\mathrm{r}=0.226, P=0.005)$, MVD $(\mathrm{r}=0.485, P<$
$0.001)$, and VM positivity $(\mathrm{r}=0.518, P<0.001)$. In addition, AGGF1 expression was positively correlated with MVD ( $\mathrm{r}=$ $0.363, P<0.001)$ and VM positivity $(\mathrm{r}=0.318, P<0.001)$. There was also a positive correlation between MVD and VM positivity $(\mathrm{r}=0.682, P<0.001)$ (Table 3$)$.

\section{Effect of UBE2C Expression, AGGFI Expression, MVD, VM Positivity, and Clinicopathological Parameters on OS}

Kaplan-Meier analysis results showed that the 5-year OS rate of 154 NSCLC patients was $20.3 \%$, the median survival time was 41.0 months, and the average OS was 45.4 \pm 2.3 months. The OS and 5-year OS rates in the UBE2Cpositive group ( $30.8 \pm 1.9$ months; $4.8 \%)$ were significantly lower than those in the UBE2C-negative group (61.9 \pm 3.2 months; 38.2\%; $\chi^{2}=49.521, P<0.001$; Figure 2A). Similarly, the OS and 5-year OS rates in the AGGF1positive group $(34.3 \pm 2.1$ months; $9.3 \%)$ were significantly lower than those in the AGGF1-negative group (58.7 \pm 2.6 months; $35.4 \% ; \chi^{2}=23.383, P<0.001$; Figure $2 \mathrm{~B}$ ). The OS and 5-year OS rates in the VM-positive group (22.6 \pm 2.0 months; $2.2 \%$ ) were significantly lower than those in the VM-negative group $\left(57.8 \pm 2.6\right.$ months; $30.2 \% ; \chi^{2}=$ $86.409, P<0.001$; Figure 2C). The OS and 5-year OS rates were $25.3 \pm 2.0$ months and $2.2 \%$ in the high-MVD group and $59.3 \pm 2.7$ months and $32.6 \%$ in the low-MVD group, respectively $\left(\chi^{2}=73.650, P<0.001\right.$; Figure 2D). Moreover, the OS and 5-year OS rates of patients with 
Table 2 The Correlation Between UBE2C, or AGGFI, or VM, or MVD and Clinicopathological Characteristics in NSCLC

\begin{tabular}{|c|c|c|c|c|c|c|c|c|c|c|c|c|}
\hline \multirow[t]{2}{*}{ Variables } & \multicolumn{3}{|l|}{ UBE2C } & \multicolumn{3}{|l|}{ AGGFI } & \multicolumn{3}{|l|}{ VM } & \multicolumn{3}{|c|}{ MVD } \\
\hline & Negative & Positive & $P$ & Negative & Positive & $\mathbf{P}$ & Negative & Positive & $P$ & Low & High & $\mathbf{P}$ \\
\hline Age (years) & & & 0.323 & & & 0.593 & & & 0.219 & & & 0.152 \\
\hline$<60$ & 19 & 32 & & 19 & 32 & & 29 & 22 & & 25 & 26 & \\
\hline$\geq 60$ & 47 & 56 & & 43 & 60 & & 69 & 34 & & 63 & 40 & \\
\hline Gender & & & 0.842 & & & 0.272 & & & 0.515 & & & 0.112 \\
\hline Female & 22 & 28 & & 17 & 33 & & 30 & 20 & & 24 & 26 & \\
\hline Male & 44 & 60 & & 45 & 59 & & 68 & 36 & & 64 & 40 & \\
\hline Smoking & & & 0.925 & & & 0.420 & & & 0.310 & & & 0.452 \\
\hline No & 38 & 50 & & 33 & 55 & & 53 & 35 & & 48 & 40 & \\
\hline Yes & 28 & 38 & & 29 & 37 & & 45 & 21 & & 40 & 26 & \\
\hline Gross Type & & & 0.925 & & & 0.734 & & & 0.117 & & & 0.083 \\
\hline Central & 37 & 50 & & 34 & 53 & & 60 & 27 & & 55 & 32 & \\
\hline Peripheral & 29 & 38 & & 28 & 39 & & 38 & 29 & & 33 & 34 & \\
\hline Histologic Type & & & 0.609 & & & 0.263 & & & 0.059 & & & 0.245 \\
\hline $\mathrm{scC}$ & 31 & 45 & & 34 & 42 & & 54 & 22 & & 47 & 29 & \\
\hline Ade & 35 & 43 & & 28 & 50 & & 44 & 34 & & 41 & 37 & \\
\hline Grade & & & 0.420 & & & 0.791 & & & 0.385 & & & 0.172 \\
\hline Well & 13 & 15 & & 10 & 18 & & 21 & 7 & & 20 & 8 & \\
\hline Moderate & 39 & 46 & & 34 & 51 & & 52 & 33 & & 48 & 37 & \\
\hline Poor & 14 & 27 & & 18 & 23 & & 25 & 16 & & 20 & 21 & \\
\hline Tumor size $(\mathrm{cm})$ & & & $0.003^{\mathrm{a}}$ & & & $0.009^{a}$ & & & $0.003^{\mathrm{a}}$ & & & $0.009^{\mathrm{a}}$ \\
\hline$\leq 3$ & 42 & 35 & & 23 & 54 & & 58 & 19 & & 52 & 25 & \\
\hline$>3$ & 24 & 53 & & 39 & 38 & & 40 & 37 & & 36 & 41 & \\
\hline LNM & & & $0.005^{\mathrm{a}}$ & & & $0.002^{\mathrm{a}}$ & & & $<0.001^{b}$ & & & $0.002^{\mathrm{a}}$ \\
\hline No & 39 & 32 & & 38 & 33 & & 59 & 12 & & 50 & 21 & \\
\hline Yes & 27 & 56 & & 24 & 59 & & 39 & 44 & & 38 & 45 & \\
\hline TNM stage & & & $0.00 \mathrm{I}^{\mathrm{a}}$ & & & $0.028^{a}$ & & & $0.00 \mathrm{I}^{\mathrm{a}}$ & & & $0.009^{\mathrm{a}}$ \\
\hline $1+\|$ & 50 & 43 & & 44 & 49 & & 69 & 24 & & 61 & 32 & \\
\hline III+IV & 16 & 45 & & 18 & 43 & & 29 & 32 & & 27 & 34 & \\
\hline
\end{tabular}

Note: ${ }^{\mathrm{a}} \mathrm{P}<0.05$; ${ }^{\mathrm{b}} \mathrm{P}<0.001$.

Abbreviations: NSCLC, non-small cell lung cancer; SCC, squamous cell carcinoma; Ade, adenocarcinoma; LNM, lymph node metastasis; TNM, tumor-node-metastasis; VM, vasculogenic mimicry; AGGFI, angiogenic factor with G patch and FHA domains I; UBE2C, ubiquitin-conjugating enzyme E2C; MVD, the microvessel density.

LNM were significantly lower than those of patients without LNM (31.3 \pm 2.0 months vs $60.6 \pm 3.3$ months; $4.3 \%$ vs $38.7 \%$; $\chi^{2}=43.688, P<0.001$; Figure $2 \mathrm{E}$ ). The OS and 5 -year OS rates in patients with stage III or IV disease were lower than those in patients with stage I or II disease (26.8 \pm 2.3 months vs $56.6 \pm 2.7$ months; $5.0 \%$ vs $29.9 \%$; $\chi^{2}$ $=53.170, P<0.001$; Figure $2 \mathrm{~F}$ ). Patients with tumors larger than $3 \mathrm{~cm}$ had lower OS and 5-year OS rates $(37.2$ \pm 2.9 months vs $52.4 \pm 3.1$ months; $14.4 \%$ vs $26.1 \%$; $\chi^{2}=$ 8.004, $P=0.005)$. However, age, sex, smoking status, gross type, histological type, and tumor grade had no significant effect on OS $(P>0.05)$.

\section{Effect of UBE2C Expression, AGGFI Expression, MVD, VM Positivity, and Clinicopathological Parameters on DFS}

Our analysis of DFS in 154 NSCLC patients showed a 5-year DFS rate of $19.2 \%$, median survival of 39.0 months, and mean DFS of $43.5 \pm 2.3$ months for all patients. The DFS and 5-year DFS rates in the UBE2Cpositive group $(29.2 \pm 1.0$ months; $5.2 \%)$ were significantly lower than those in the UBE2C-negative group (59.4 \pm 3.3 months; 35.2\%; $\chi^{2}=46.156, P<0.001$; Figure 3A). The DFS and 5-year DFS rates in the AGGF1-positive group (32.8 \pm 2.1 months; $10.0 \%)$ were 
Table 3 Correlation Among UBE2C, AGGFI, VM, and MVD in NSCLC

\begin{tabular}{|c|c|c|c|c|c|c|c|c|c|c|c|c|}
\hline \multirow[t]{2}{*}{ Variables } & \multicolumn{2}{|c|}{ UBE2C } & \multirow[b]{2}{*}{$r$} & \multirow[b]{2}{*}{$P$} & \multicolumn{2}{|c|}{ AGGFI } & \multirow[b]{2}{*}{$r$} & \multirow[b]{2}{*}{$P$} & \multicolumn{2}{|c|}{ VM } & \multirow[b]{2}{*}{$r$} & \multirow[b]{2}{*}{$P$} \\
\hline & Negative & Positive & & & Negative & Positive & & & Negative & Positive & & \\
\hline MVD & & & 0.485 & $<0.001^{b}$ & & & 0.363 & $<0.001^{b}$ & & & 0.682 & $<0.001^{\mathrm{b}}$ \\
\hline Low & 56 & 32 & & & 49 & 39 & & & 81 & 7 & & \\
\hline High & 10 & 56 & & & 13 & 53 & & & 17 & 49 & & \\
\hline UBE2C & & & & & & & 0.226 & $0.005^{\mathrm{a}}$ & & & 0.518 & $<0.001^{b}$ \\
\hline Negative & & & & & 35 & 31 & & & 61 & 5 & & \\
\hline Positive & & & & & 27 & 61 & & & 37 & 51 & & \\
\hline AGGFI & & & & & & & & & & & 0.318 & $<0.001^{b}$ \\
\hline Negative & & & & & & & & & 51 & 11 & & \\
\hline Positive & & & & & & & & & 47 & 45 & & \\
\hline
\end{tabular}

Notes: ${ }^{\mathrm{a} P}<0.05 ;{ }^{\mathrm{b}} \mathrm{P}<0.001$.

Abbreviations: VM, vasculogenic mimicry; AGGFI, angiogenic factor with G patch and FHA domains I; UBE2C, ubiquitin-conjugating enzyme E2C; MVD, the microvessel density.

significantly lower than those in the AGGF1-negative group (55.8 \pm 3.5 months; $32.1 \% ; \chi^{2}=20.113, P<0.001$; Figure 3B). Furthermore, the DFS and 5-year DFS rates in the VM-positive group were $20.8 \pm 2.0$ months and $2.4 \%$, respectively, whereas those in the VM-negative group were $55.8 \pm 2.6$ months and $28.5 \%$, respectively, and the differences between the two groups were statistically significant $\left(\chi^{2}=86.340, P<0.001\right.$; Figure 3 C).
The DFS and 5-year DFS rates in the high-MVD group were significantly lower than those in the low-MVD group (23.8 \pm 2.0 months vs $56.8 \pm 2.7$ months; $2.5 \%$ vs $30.3 \% ; \chi^{2}=69.609, P<0.001$; Figure 3D). In addition, the DFS and 5-year DFS rates were significantly lower in the group with LNM than in the group without LNM (29.5 \pm 1.9 months vs $58.6 \pm 3.4$ months; $3.0 \%$ vs $37.5 \%$; $\chi^{2}=44.624, P<0.001$; Figure 3E). The DFS and 5-year


Figure 2 Kaplan-Meier analysis of OS in NSCLC patients. (A) Correlation between OS and UBE2C $\left(\chi^{2}=49.521, P<0.00 \mathrm{I}\right)$. (B) Correlation between OS and AGGFI $\left(\chi^{2}=\right.$ 23.383, $P<0.001)$. (C) Correlation between OS and VM $\left(\chi^{2}=86.409, P<0.001\right)$. (D) Correlation between OS and MVD $\left(\chi^{2}=73.650, P<0.001\right)$. (E) Correlation between OS and LNM $\left(\chi^{2}=43.688, P<0.001\right)$. (F) Correlation between OS and TNM stage $\left(\chi^{2}=53.170, P<0.001\right)$.

Abbreviations: NSCLC, non-small cell lung cancer; UBE2C, ubiquitin-conjugating enzyme E2C; AGGFI, angiogenic factor with Gpatch and FHA domains I; VM, vasculogenic mimicry; MVD, the microvessel density; OS, overall survival; LNM, lymph node metastasis; TNM, tumor-node-metastasis. 

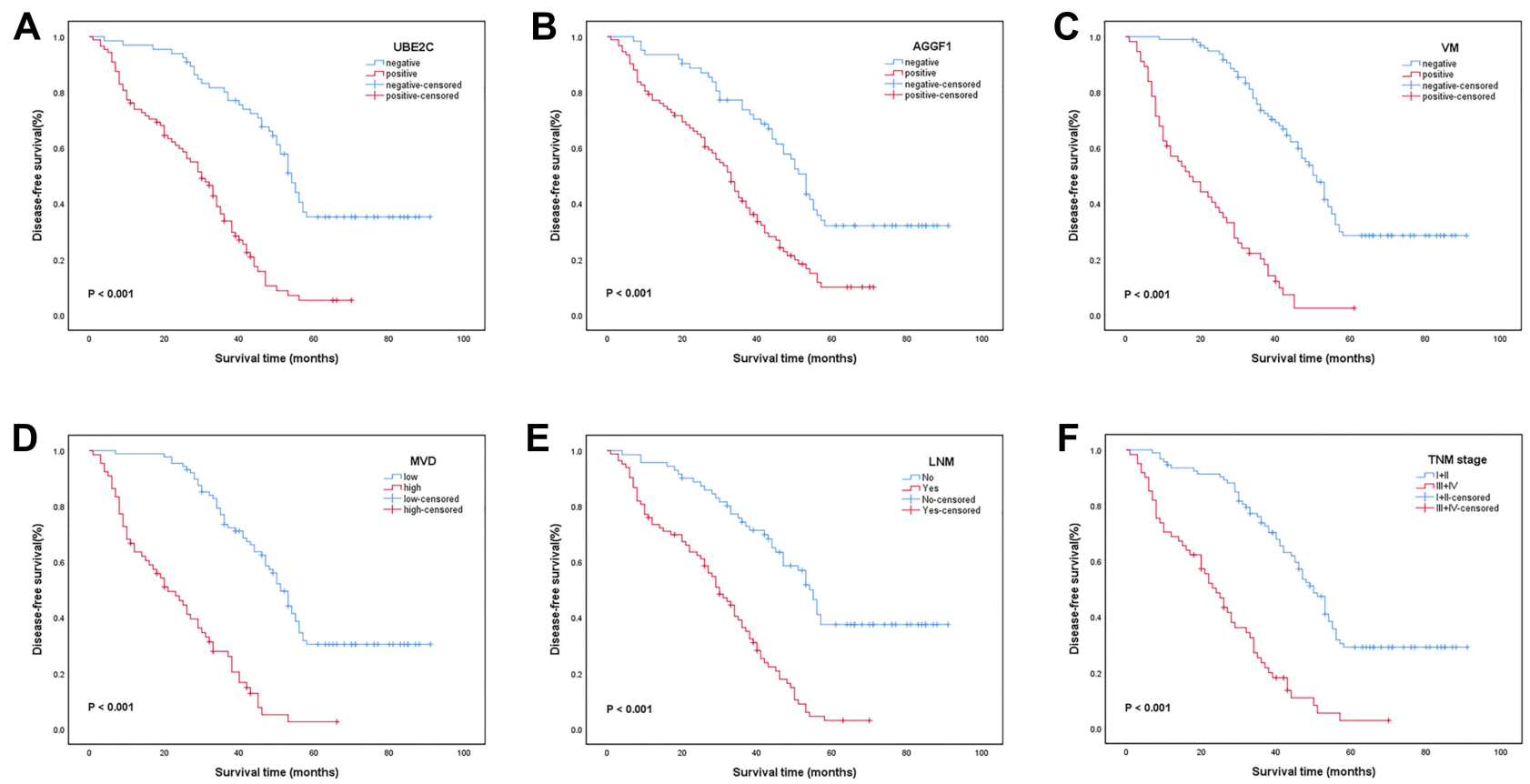

Figure 3 Kaplan-Meier analysis of DFS in NSCLC patients. (A) Correlation between DFS and UBE2C $\left(\chi^{2}=46.156, P<0.001\right)$. (B) Correlation between DFS and AGGFI $\left(\chi^{2}\right.$ $=20.113, P<0.001)$. (C) Correlation between DFS and VM $\left(\chi^{2}=86.340, P<0.001\right)$. (D) Correlation between DFS and MVD $\left(\chi^{2}=69.609, P<0.001\right)$. (E) Correlation between DFS and LNM $\left(\chi^{2}=44.624, P<0.00 I\right)$. (F) Correlation between DFS and TNM stage $\left(\chi^{2}=53.613, P<0.001\right)$.

Abbreviations: NSCLC, non-small cell lung cancer; UBE2C, ubiquitin-conjugating enzyme E2C; AGGFI, angiogenic factor with Gpatch and FHA domains I; VM, vasculogenic mimicry; MVD, the microvessel density; DFS, disease-free survival; LNM, lymph node metastasis; TNM, tumor-node-metastasis.

DFS rates were significantly lower in patients with stage III or IV disease $(25.1 \pm 2.2$ months; $2.7 \%)$ than in patients with stage I or II disease $\left(54.6 \pm 2.8 ; 29.1 \% ; \chi^{2}\right.$ $=53.613, P<0.001$; Figure $3 \mathrm{~F}$ ). The DFS and 5-year DFS rates were lower in patients with tumors larger than $3 \mathrm{~cm}(35.5 \pm 2.9$ months vs $50.2 \pm 3.1$ months; $13.3 \%$ vs $\left.24.8 \% ; \chi^{2}=7.841, P=0.005\right)$. However, other clinicopathological parameters, such as age and sex, had no significant effect on DFS $(P>0.05)$.

\section{Univariate and Multivariate Analyses}

We then analyzed the factors affecting the prognosis of NSCLC using the Cox risk regression model. Univariate analysis revealed that UBE2C expression, AGGF1 expression, MVD value, positive VM, tumor size, LNM, and TNM stage were significantly correlated with OS and DFS, and were important factors affecting the prognosis of patients with NSCLC (Tables 4 and 5). Multivariate analysis showed that UBE2C expression, AGGF1 expression, MVD value, positive VM, tumor size, LNM, and TNM stage were closely related to OS and DFS and could be used as independent prognostic indicators of NSCLC (Tables 4 and 5).

\section{Discussion}

Research on invasion and metastasis of NSCLC can facilitate more effective measures and improve its prognosis. Huang et al found that exosomes could promote the invasion and metastasis of NSCLC. ${ }^{27}$ In this study, for the first time, in order to identify novel biological factors that might predict the infiltration and metastasis of NSCLC, the expressions of UBE2C and AGGF1 proteins were detected simultaneously and their relationships with VM, MVD, and prognosis were explored.

$\mathrm{UBE} 2 \mathrm{C}$ is essential for ubiquitination. Under the control of the UBE2C protein and after a series of enzymatic reactions, the substrate protein is ubiquitinated and degraded. The normal progress of this process is related to successful completion of the cell cycle and signal transduction. $^{28}$ Our results showed that UBE2C is overexpressed in NSCLC tissues (57.1\%) and is rarely expressed in normal tissues $(15.6 \%)$. We found that UBE2C overexpression was associated with a larger tumor volume, LNM, and later clinical stage, suggesting that it might be involved in the growth and metastasis of NSCLC. Through Kaplan-Meier survival analysis and univariate and multivariate analyses, we observed that the overexpression of UBE2C leads to a shorter OS and 
Table 4 Univariate and Multivariate Analysis of OS and Clinicopathological Variables

\begin{tabular}{|c|c|c|c|c|c|}
\hline \multirow[t]{2}{*}{ Variables } & \multirow[t]{2}{*}{ Number } & \multicolumn{2}{|c|}{ Univariable Analysis } & \multicolumn{2}{|c|}{ Multivariable Analysis } \\
\hline & & HR (95\% Cl) & $P$ & HR (95\% Cl) & $P$ \\
\hline UBE2C & & $4.059(2.676-6.158)$ & $<0.001^{b}$ & $1.946(1.202-3.150)$ & $0.007^{\mathrm{a}}$ \\
\hline Negative & 66 & & & & \\
\hline Positive & 88 & & & & \\
\hline AGGFI & & $2.582(1.728-3.858)$ & $<0.00 \mathrm{I}^{\mathrm{b}}$ & $1.909(1.195-3.051)$ & $0.007^{\mathrm{a}}$ \\
\hline Negative & 62 & & & & \\
\hline Positive & 92 & & & & \\
\hline VM & & $5.773(3.833-8.696)$ & $<0.00 \mathrm{I}^{\mathrm{b}}$ & $2.107(1.226-3.622)$ & $0.007^{\mathrm{a}}$ \\
\hline Negative & 98 & & & & \\
\hline Positive & 56 & & & & \\
\hline MVD & & $5.124(3.408-7.704)$ & $<0.00 \mathrm{I}^{\mathrm{b}}$ & $2.490(1.473-4.210)$ & $0.00 I^{a}$ \\
\hline Low & 88 & & & & \\
\hline High & 66 & & & & \\
\hline Age (years) & & $0.739(0.502-1.088)$ & 0.125 & - & - \\
\hline$<60$ & 51 & & & & \\
\hline$\geq 60$ & 103 & & & & \\
\hline Gender & & $1.214(0.823-1.79 \mid)$ & 0.328 & - & - \\
\hline Female & 50 & & & & \\
\hline Male & 104 & & & & \\
\hline Smoking & & $1.074(0.740-1.558)$ & 0.707 & - & - \\
\hline No & 88 & & & & \\
\hline Yes & 66 & & & & \\
\hline Gross Type & & $0.850(0.583-1.240)$ & 0.399 & - & - \\
\hline Central & 87 & & & & \\
\hline Peripheral & 67 & & & & \\
\hline Histologic Type & & $1.033(0.7 \mid 3-1.497)$ & 0.863 & - & - \\
\hline SCC & 76 & & & & \\
\hline Ade & 78 & & & & \\
\hline Grade & & I.I73(0.887-I.552) & 0.263 & - & - \\
\hline Well & 28 & & & & \\
\hline Moderate & 85 & & & & \\
\hline Poor & 41 & & & & \\
\hline Tumor size $(\mathrm{cm})$ & & $1.690(I .165-2.45 \mathrm{I})$ & $0.006^{\mathrm{a}}$ & $1.670(1.075-2.594)$ & $0.023^{\mathrm{a}}$ \\
\hline$\leq 3$ & 77 & & & & \\
\hline$>3$ & 77 & & & & \\
\hline LNM & & $3.593(2.398-5.383)$ & $<0.00 \mathrm{I}^{\mathrm{b}}$ & I.846(I.162-2.934) & $0.009^{\mathrm{a}}$ \\
\hline No & 71 & & & & \\
\hline Yes & 83 & & & & \\
\hline
\end{tabular}

(Continued) 
Table 4 (Continued).

\begin{tabular}{|l|l|l|l|l|l|}
\hline \multirow{2}{*}{ Variables } & \multirow{2}{*}{ Number } & \multicolumn{3}{|l|}{ Univariable Analysis } & \multicolumn{2}{l|}{ Multivariable Analysis } \\
\cline { 3 - 6 } & & HR $(95 \%$ Cl) & $P$ & HR (95\% CI) & $P$ \\
\hline TNM stage & & $3.888(2.629-5.748)$ & $<0.00 I^{\mathrm{b}}$ & $2.837(1.845-4.363)$ & $<0.00 \mathrm{I}^{\mathrm{b}}$ \\
\hline $\begin{array}{l}\text { I+II } \\
\text { III+IV }\end{array}$ & 93 & & & & \\
\hline
\end{tabular}

Notes: ${ }^{\mathrm{a}} P<0.05 ;{ }^{\mathrm{b}} p<0.001$.

Abbreviations: SCC, squamous cell carcinoma; Ade, adenocarcinoma; LNM, lymph node metastasis; TNM, tumor-node-metastasis; VM, vasculogenic mimicry; AGGFI, angiogenic factor with $\mathrm{G}$ patch and FHA domains I; UBE2C, ubiquitin-conjugating enzyme E2C; MVD, the microvessel density; OS, overall survival.

Table 5 Univariate and Multivariate Analysis of DFS and Clinicopathological Variables

\begin{tabular}{|c|c|c|c|c|c|}
\hline \multirow[t]{2}{*}{ Variables } & \multirow[t]{2}{*}{ Number } & \multicolumn{2}{|c|}{ Univariable Analysis } & \multicolumn{2}{|c|}{ Multivariable Analysis } \\
\hline & & HR (95\% Cl) & $P$ & HR $(95 \% \mathrm{Cl})$ & $P$ \\
\hline UBE2C & & $3.853(2.549-5.822)$ & $<0.001^{b}$ & $1.812(1.118-2.935)$ & $0.016^{\mathrm{a}}$ \\
\hline Negative & 66 & & & & \\
\hline Positive & 88 & & & & \\
\hline AGGFI & & $2.388(1.609-3.546)$ & $<0.00 \mathrm{I}^{\mathrm{b}}$ & $1.778(1.116-2.835)$ & $0.016^{\mathrm{a}}$ \\
\hline Negative & 62 & & & & \\
\hline Positive & 92 & & & & \\
\hline VM & & $5.802(3.848-8.747)$ & $<0.001^{b}$ & $2.286(1.333-3.920)$ & $0.003^{\mathrm{a}}$ \\
\hline Negative & 98 & & & & \\
\hline Positive & 56 & & & & \\
\hline MVD & & $4.906(3.269-7.363)$ & $<0.001^{\mathrm{b}}$ & $2.376(I .42 I-3.972)$ & $0.001^{\mathrm{a}}$ \\
\hline Low & 88 & & & & \\
\hline High & 66 & & & & \\
\hline Age (years) & & $0.758(0.516-1.115)$ & 0.160 & - & - \\
\hline$<60$ & 51 & & & & \\
\hline$\geq 60$ & 103 & & & & \\
\hline Gender & & $1.215(0.824-1.790)$ & 0.326 & - & - \\
\hline Female & 50 & & & & \\
\hline Male & 104 & & & & \\
\hline Smoking & & I.I49(0.794-I.662) & 0.462 & - & - \\
\hline No & 88 & & & & \\
\hline Yes & 66 & & & & \\
\hline Gross Type & & $0.843(0.579-1.228)$ & 0.374 & - & - \\
\hline Central & 87 & & & & \\
\hline Peripheral & 67 & & & & \\
\hline Histologic Type & & $1.002(0.693-1.448)$ & 0.992 & - & - \\
\hline SCC & 76 & & & & \\
\hline Ade & 78 & & & & \\
\hline
\end{tabular}


Table 5 (Continued).

\begin{tabular}{|c|c|c|c|c|c|}
\hline \multirow[t]{2}{*}{ Variables } & \multirow[t]{2}{*}{ Number } & \multicolumn{2}{|c|}{ Univariable Analysis } & \multicolumn{2}{|c|}{ Multivariable Analysis } \\
\hline & & HR (95\% Cl) & $P$ & HR $(95 \% \mathrm{Cl})$ & $P$ \\
\hline Grade & & $1.165(0.882-1.539)$ & 0.281 & - & - \\
\hline Well & 28 & & & & \\
\hline Moderate & 85 & & & & \\
\hline Poor & 41 & & & & \\
\hline Tumor size $(\mathrm{cm})$ & & $1.678(1.159-2.430)$ & $0.006^{\mathrm{a}}$ & I.666(I.073-2.588) & $0.023^{\mathrm{a}}$ \\
\hline$\leq 3$ & 77 & & & & \\
\hline$>3$ & 77 & & & & \\
\hline LNM & & $3.660(2.440-5.488)$ & $<0.00 \mathrm{I}^{\mathrm{b}}$ & $1.948(1.224-3.100)$ & $0.005^{\mathrm{a}}$ \\
\hline No & 71 & & & & \\
\hline Yes & 83 & & & & \\
\hline TNM stage & & $3.934(2.657-5.825)$ & $<0.001^{b}$ & $2.800(I .822-4.30 I)$ & $<0.001^{b}$ \\
\hline$|+| \mid$ & 93 & & & & \\
\hline III+IV & 61 & & & & \\
\hline
\end{tabular}

Notes: ${ }^{a} p<0.05 ;{ }^{b} p<0.001$.

Abbreviations: SCC, squamous cell carcinoma; Ade, adenocarcinoma; LNM, lymph node metastasis; TNM, tumor-node-metastasis; VM, vasculogenic mimicry; AGGFI, angiogenic factor with $\mathrm{G}$ patch and FHA domains I; UBE2C, ubiquitin-conjugating enzyme E2C; MVD, the microvessel density; DFS, disease-free survival.

DFS in patients with NSCLC, suggesting that UBE2C could be used to predict the prognosis of NSCLC. Dastsooz et al concluded through bioinformatics analysis that UBE2C was overexpressed in 27 malignant tumors, including bladder cancer and leukemia, and was negatively correlated with OS and DFS. ${ }^{29}$ Wang et al and Guo et al confirmed through cytological experiments that the overexpression of UBE2C in pancreatic cancer and NSCLC was related to the proliferation and invasion of tumor cells and was negatively correlated with OS. ${ }^{13,30}$ Therefore, our findings are consistent with those of existing studies.

AGGF1 is an important angiogenic factor that promotes angiogenesis, and has been verified in many studies. Yao et al confirmed that AGGF1 plays an important role in regulating mouse endothelial progenitor cells, and knocking out this gene was found to lead to angiogenesis disorders. ${ }^{31}$ Zhang et al indicated that AGGF1 is crucial for both physiological and pathological angiogenesis, and defects in this gene were shown to inhibit tumor growth. ${ }^{20}$ Studies have shown that AGGF1 is overexpressed in liver, colorectal, and gastric cancer and is negatively correlated with OS and DFS. However, the expression of AGGF1 in NSCLC and its relationship with prognosis remain unclear. In this study, we used immunohistochemistry to observe the expression of
AGGF1 in NSCLC for the first time. The positive rates of AGGF1 in NSCLC tissues and normal tissues were $59.7 \%$ and $25.3 \%$, respectively, and the overexpression of AGGF1 was related to tumor size, LNM, and later TNM stage, indicating that AGGF1 is involved in the progression of NSCLC. Kaplan-Meier survival analysis, as well as univariate and multivariate analyses, showed that the overexpression of AGGF1 resulted in a shorter OS and DFS. Accordingly, the expression of AGGF1 and its prognostic implications are similar between NSCLC and other tumors.

We aimed to explore the effects of UBE2C and AGGF1 on angiogenesis by analyzing the relationships among UBE2C, AGGF1, MVD, and VM in NSCLC and further evaluating the value of UBE2C and AGGF1 in predicting the infiltration, metastasis, and prognosis of this disease. This study is the first to jointly detect the expression of UBE2C and AGGF1, as well as MVD and VM, in NSCLC and it is therefore innovative. Our results, consistent with those of previous studies, demonstrate that high MVD and VM positivity are associated with a larger tumor volume, LNM, later clinical stage, and a shorter OS and DFS, suggesting that tumor angiogenesis promotes the growth and metastasis of NSCLC and leads to poor prognosis. ${ }^{18,32,33}$ In addition, we found that both UBE2C 
and AGGF1 were positively correlated with MVD and VM in NSCLC, indicating that both UBE2C and AGGF1 could possibly promote angiogenesis in this disease. Zhang et al found that after silencing UBE2C, the expression levels of VEGF and MMP-9, which are recognized vascular factors, were also decreased, suggesting that UBE2C might have a regulatory effect on angiogenesis. ${ }^{17}$ Shen et al found that UBE2C was positively correlated with MVD and VM in breast cancer. ${ }^{18}$ Furthermore, Tu et al demonstrated a positive correlation among AGGF1, VEGF, and MVD in hepatocellular carcinoma. ${ }^{23}$ From these results, it could be concluded that UBE2C and AGGF1 might be involved in the promotion of angiogenesis in various tumors, including NSCLC. In addition, relevant literature has shown that the ubiquitination of UBE2C can regulate angiogenesis by regulating VEGFR, NOTCH signaling, and WNT signaling, among others. ${ }^{34}$ Zhang et al found that AGGF1 promotes angiogenesis by regulating the $\mathrm{PI} 3 \mathrm{~K}-\mathrm{AKT}$ pathway in mice. ${ }^{20}$ However, further experiments are required to identify the pathways through which UBE2C and AGGF1 promote angiogenesis in NSCLC. Furthermore, the aforementioned effects of UBE2C and AGGF1 on angiogenesis are mainly mediated by vascular endothelial cells. To date, there has been no study on the mechanisms by which UBE2C and AGGF1 promote the formation of endothelial cellindependent VM. Studies have shown that high expression of both UBE2C and AGGF1 promotes epithelialmesenchymal transition (EMT). ${ }^{13,15,35}$ The formation of VM is closely related to EMT, and the upregulation of EMT-related factors can promote the formation of VM. $^{36,37}$ Therefore, we concluded that UBE2C and AGGF1 might promote VM formation by promoting EMT. In addition, from our results, we can see that there is a positive correlation between UBE2C and AGGF1, further illustrating the importance of UBE2C in angiogenesis. However, it is still unclear how these two interact. Studies have shown that UBE2C, like AGGF1, can regulate the PI3K-AKT-mTOR pathway, which plays a key role in angiogenesis, ${ }^{38-40}$ suggesting that UBE2C and AGGF1 may have similar effects on angiogenesis. In this study, owing to the limited conditions, the research sample size was not large enough and only one experimental method was used. Thus, the specific mechanisms by which UBE2C and AGGF1 promote angiogenesis need to be studied further. In conclusion, we have demonstrated that the overexpression of UBE2C and AGGF1 in NSCLC is associated with angiogenesis and leads to a poor prognosis, suggesting that UBE2C- and AGGF1overexpressing NSCLC may be more prone to invasion and metastasis. Therefore, UBE2C and AGGF1 can be considered as possible biological markers for predicting the infiltration, metastasis, and prognosis of NSCLC.

\section{Funding}

There is no funding to report.

\section{Disclosure}

The authors have declared that no competing interests exist.

\section{References}

1. Sung H, Ferlay J, Siegel RL, et al. Global cancer statistics 2020: GLOBOCAN estimates of incidence and mortality worldwide for 36 cancers in 185 countries. CA Cancer J Clin. 2021;71(3):209-249. doi: $10.3322 /$ caac. 21660

2. Allemani C, Matsuda T, Di Carlo V, et al. Global surveillance of trends in cancer survival 2000-14 (CONCORD-3): analysis of individual records for 37513025 patients diagnosed with one of 18 cancers from 322 population-based registries in 71 countries. Lancet. 2018;391(10125):1023-1075. doi:10.1016/s0140-6736(17) 33326-3

3. Ettinger DS, Wood DE, Aisner DL, et al. Non-small cell lung cancer, Version 5.2017, NCCN clinical practice guidelines in oncology. $J$ Natl Compr Canc Netw. 2017;15(4):504-535. doi:10.6004/ jncen.2017.0050

4. Yuan M, Huang LL, Chen JH, Wu J, Xu Q. The emerging treatment landscape of targeted therapy in non-small-cell lung cancer. Signal Transduct Target Ther. 2019;4:61. doi:10.1038/s41392-019-0099-9

5. Gupta GP, Massagué J. Cancer metastasis: building a framework. Cell. 2006;127(4):679-695. doi:10.1016/j.cell.2006.11.001

6. Jeong JH, Ojha U, Lee YM. Pathological angiogenesis and inflammation in tissues. Arch Pharm Res. 2021;44(1):1-15. doi:10.1007/ s12272-020-01287-2

7. Daum S, Hagen H, Naismith E, Wolf D, Pircher A. The role of anti-angiogenesis in the treatment landscape of non-small cell lung cancer - new combinational approaches and strategies of neovessel inhibition. Front Cell Dev Biol. 2020;8:610903. doi:10.3389/ fcell.2020.610903

8. Pathak AP, Hochfeld WE, Goodman SL, Pepper MS. Circulating and imaging markers for angiogenesis. Angiogenesis. 2008;11 (4):321-335. doi:10.1007/s10456-008-9119-z

9. Maniotis AJ, Folberg R, Hess A, et al. Vascular channel formation by human melanoma cells in vivo and in vitro: vasculogenic mimicry. Am J Pathol. 1999;155(3):739-752. doi:10.1016/s0002-9440(10) 65173-5

10. Viallard C, Larrivée B. Tumor angiogenesis and vascular normalization: alternative therapeutic targets. Angiogenesis. 2017;20 (4):409-426. doi:10.1007/s10456-017-9562-9

11. van Ree JH, Jeganathan KB, Malureanu L, van Deursen JM. Overexpression of the E2 ubiquitin-conjugating enzyme UbcH10 causes chromosome missegregation and tumor formation. $J$ Cell Biol. 2010;188(1):83-100. doi:10.1083/jcb.200906147

12. Wang R, Song Y, Liu X, et al. UBE2C induces EMT through Wnt/ $\beta$-catenin and $\mathrm{PI} 3 \mathrm{~K} / \mathrm{Akt}$ signaling pathways by regulating phosphorylation levels of Aurora-A. Int J Oncol. 2017;50(4):1116-1126. doi:10.3892/ijo.2017.3880 
13. Wang $\mathrm{X}$, Yin L, Yang L, et al. Silencing ubiquitin-conjugating enzyme $2 \mathrm{C}$ inhibits proliferation and epithelial-mesenchymal transition in pancreatic ductal adenocarcinoma. FEBS J. 2019;286 (24):4889-4909. doi:10.1111/febs.15134

14. Xiong Y, Lu J, Fang Q, et al. UBE2C functions as a potential oncogene by enhancing cell proliferation, migration, invasion, and drug resistance in hepatocellular carcinoma cells. Biosci Rep. 2019;39:4. doi:10.1042/bsr20182384

15. Jin D, Guo J, Wu Y, et al. UBE2C, directly targeted by miR-548e-5p, increases the cellular growth and invasive abilities of cancer cells interacting with the EMT marker protein zinc finger E-box binding homeobox 1/2 in NSCLC. Theranostics. 2019;9(7):2036-2055. doi: $10.7150 /$ thno. 32738

16. Liu Y, Zhao R, Chi S, et al. UBE2C is upregulated by estrogen and promotes epithelial-mesenchymal transition via p53 in endometrial cancer. Mol Cancer Res. 2020;18(2):204-215. doi:10.1158/15417786.Mcr-19-0561

17. Zhang Z, Liu P, Wang J, et al. Ubiquitin-conjugating enzyme E2C regulates apoptosis-dependent tumor progression of non-small cell lung cancer via ERK pathway. Med Oncol. 2015;32(5):149. doi:10.1007/s12032-015-0609-8

18. Shen R, Wu T, Huang P, Shao Q, Chen M. The clinicopathological significance of ubiquitin-conjugating enzyme E2C, leucine-rich repeated-containing $\mathrm{G}$ protein-coupled receptor, WW domain-containing oxidoreductase, and vasculogenic mimicry in invasive breast carcinoma. Medicine (Baltimore). 2019;98(16): e15232. doi:10.1097/md.0000000000015232

19. Tian XL, Kadaba R, You SA, et al. Identification of an angiogenic factor that when mutated causes susceptibility to Klippel-Trenaunay syndrome. Nature. 2004;427(6975):640-645. doi:10.1038/nature02320

20. Zhang T, Yao Y, Wang J, et al. Haploinsufficiency of Klippel-Trenaunay syndrome gene Aggf1 inhibits developmental and pathological angiogenesis by inactivating PI3K and AKT and disrupts vascular integrity by activating VE-cadherin. Hum Mol Genet. 2016;25(23):5094-5110. doi:10.1093/hmg/ddw273

21. Yang C, Zheng J, Xue Y, et al. The effect of MCM3AP-AS1/miR211/KLF5/AGGF1 axis regulating glioblastoma angiogenesis. Front Mol Neurosci. 2017;10:437. doi:10.3389/fnmol.2017.00437

22. Zhang X, Sun H, Chen W, He X. Elevated expression of AGGF1 predicts poor prognosis and promotes the metastasis of colorectal cancer. BMC Cancer. 2019;19(1):1252. doi:10.1186/s12885-0196474-7

23. Tu J, Ying X, Zhang D, et al. High expression of angiogenic factor AGGF1 is an independent prognostic factor for hepatocellular carcinoma. Oncotarget. 2017;8(67):111623-111630. doi:10.18632/ oncotarget.22880

24. Yao HH, Wang BJ, Wu Y, Huang Q. High expression of angiogenic factor with G-Patch and FHA Domain1 (AGGF1) predicts poor prognosis in gastric cancer. Med Sci Monit. 2017;23:1286-1294. doi: $10.12659 / \mathrm{msm} .903248$

25. Ma L, Yang R, Gu J, Jiang H, Li H. The expression of AGGF1, FOXC2, and E-cadherin in esophageal carcinoma and their clinical significance. Medicine (Baltimore). 2020;99(37):e22173. doi:10.1097/md.0000000000022173

Cancer Management and Research

\section{Publish your work in this journal}

Cancer Management and Research is an international, peer-reviewed open access journal focusing on cancer research and the optimal use of preventative and integrated treatment interventions to achieve improved outcomes, enhanced survival and quality of life for the cancer patient.
26. Weidner N, Semple JP, Welch WR, Folkman J. Tumor angiogenesis and metastasis-correlation in invasive breast carcinoma. $N$ Engl J Med. 1991;324(1):1-8. doi:10.1056/nejm199101033240101

27. Huang W, Yan Y, Liu Y, et al. Exosomes with low miR-34c-3p expression promote invasion and migration of non-small cell lung cancer by upregulating integrin $\alpha 2 \beta 1$. Signal Transduct Target Ther. 2020;5(1):39. doi:10.1038/s41392-020-0133-y

28. Presta I, Novellino F, Donato A, et al. UbcH10 a major actor in cancerogenesis and a potential tool for diagnosis and therapy. Int J Mol Sci. 2020;21:6. doi:10.3390/ijms21062041

29. Dastsooz H, Cereda M, Donna D, Oliviero S, Oliviero A. Comprehensive bioinformatics analysis of UBE2C in cancers. Int J Mol Sci. 2019;20:9. doi:10.3390/ijms20092228

30. Guo J, Wu Y, Du J, et al. Deregulation of UBE2C-mediated autophagy repression aggravates NSCLC progression. Oncogenesis. 2018;7(6):49. doi:10.1038/s41389-018-0054-6

31. Yao Y, Li Y, Song Q, et al. Angiogenic factor AGGF1-primed endothelial progenitor cells repair vascular defect in diabetic mice. Diabetes. 2019;68(8):1635-1648. doi:10.2337/db18-1178

32. Dong Y, Ma G, Liu Y, Lu S, Liu L. Prognostic value of microvessel density in head and neck squamous cell carcinoma: a meta-analysis. Dis Markers. 2020;2020:8842795. doi:10.1155/2020/8842795

33. Mitra D, Bhattacharyya S, Alam N, et al. Phosphorylation of EphA2 receptor and vasculogenic mimicry is an indicator of poor prognosis in invasive carcinoma of the breast. Breast Cancer Res Treat. 2020;179(2):359-370. doi:10.1007/s10549-019-05482-8

34. Rabellino A, Andreani C, Scaglioni PP. Roles of ubiquitination and sumoylation in the regulation of angiogenesis. Curr Issues Mol Biol. 2020;35:109-126. doi:10.21775/cimb.035.109

35. Yao HH, Zhao YJ, He YF, Huang DB, Wang W. Knockdown of AGGF1 inhibits the invasion and migration of gastric cancer via epithelial-mesenchymal transition through $\mathrm{Wnt} / \beta$-catenin pathway. Cancer Cell Int. 2019;19:41. doi:10.1186/s12935-019-0765-6

36. Liu Q, Qiao L, Liang N, et al. The relationship between vasculogenic mimicry and epithelial-mesenchymal transitions. J Cell Mol Med. 2016;20(9):1761-1769. doi:10.1111/jcmm.12851

37. Zhang X, Cui P, Ding B, et al. Netrin-1 elicits metastatic potential of non-small cell lung carcinoma cell by enhancing cell invasion, migration and vasculogenic mimicry via EMT induction. Cancer Gene Ther. 2018;25(1-2):18-26. doi:10.1038/s41417-017-0008-8

38. Guo L, Ding Z, Huang N, Huang Z, Zhang N, Xia Z. Forkhead Box M1 positively regulates UBE2C and protects glioma cells from autophagic death. Cell Cycle. 2017;16(18):1705-1718. doi:10.1080/ 15384101.2017.1356507

39. Chiang AJ, Li CJ, Tsui KH, et al. UBE2C drives human cervical cancer progression and is positively modulated by mTOR. Biomolecules. 2020;11(1):37. doi:10.3390/biom11010037

40. Karar J, Maity A. PI3K/AKT/mTOR pathway in angiogenesis. Front Mol Neurosci. 2011;4:51. doi:10.3389/fnmol.2011.00051
The manuscript management system is completely online and includes a very quick and fair peer-review system, which is all easy to use.

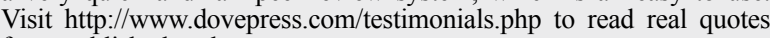
from published authors.

\section{Dovepress}

